\title{
A Concepção Freudiana de Experiência ${ }^{1}$
}

\author{
Eduardo Rotstein ${ }^{2}$ \\ Angélica Bastos \\ Universidade Federal do Rio de Janeiro
}

\begin{abstract}
RESUMO - O tema deste artigo é a concepção de experiência na obra de Freud, problematizada pela indissociabilidade entre pesquisa e tratamento psicanalítico. Com a premissa de que a psicanálise possui fundamento empírico e a constatação da inexistência de definição explícita de 'experiência' no texto freudiano, seus objetivos consistem em circunscrever a concepção freudiana de experiência, examinar os critérios científicos assumidos por seu fundador e demarcar a natureza de sua práxis. A investigação da etimologia do termo 'experiência', da distinção conceitual entre esta e a vivência na trama conceitual freudiana, do caráter empírico da investigação em psicanálise, bem como de sua natureza clínica, ambos reiterados na referida obra, levam a concluir por um duplo sentido do termo.
\end{abstract}

Palavras-chave: experiência; psicanálise; ciência; Freud; clínica.

\section{The Freudian Conception of Experience}

\begin{abstract}
The theme of this article is the conception of experience in Freud's work, which is problematic due to the inseparability between research and psychoanalytic treatment. With the premise that psychoanalysis has an empirical foundation and establishing the lack of an explicit definition of 'experience' in the Freudian text, the objectives of this study are to circumscribe the Freudian conception of experience, to examine the scientific criteria given by its founder and to determine the nature of its praxis. The etymological study of the word 'experience', the conceptual distinction between this conception and the one used in the Freudian conceptual scheme, the empirical character of research in psychoanalysis, as well as its clinical nature, both reaffirmed Freud's work, lead to the conclusion of a two-way term.
\end{abstract}

Keywords: experience; psychoanalysis; science; Freud; clinical.

A psicanálise repousa primordialmente sobre a experiência, não sobre a especulação ou a imaginação. Possui, portanto, fundamento empírico, ao qual se reportam direta ou indiretamente conceitos fundamentais, como a transferência e o inconsciente.

Embora a experiência não seja definida por Freud explicitamente como um conceito fundamental, a concepção que dela se faz o psicanalista determina a orientação que imprime à pesquisa e ao tratamento, condicionando a tarefa analisante que seu ato autoriza, bem como, de modo mais abrangente, o exercício de seu ofício do início ao fim de uma análise. Circunscrever a concepção de experiência na obra freudiana, examinar sua relação com os critérios científicos reconhecidos por Freud e delinear os contornos que assume em função da natureza de sua práxis, constituem os objetivos do presente artigo.

Em psicanálise, pesquisa e tratamento caminham juntos, sendo até certo ponto indissociáveis. Tal como descrita por Freud, a investigação psicanalítica mantinha em seu horizonte critérios de cientificidade, cujo cumprimento viria assegurar-lhe um lugar entre as ciências de seu tempo. Essa aspiração envolve exigências epistemológicas e metodológicas que

1 Agradecemos o apoio do CNPq, FAPERJ (bolsa nota 10) e CAPES. Este trabalho constitui desdobramento parcial da dissertação de mestrado "Inconsciente e experiência analítica", de Eduardo Rotstein, realizada no Programa de Pós-Graduação em Teoria Psicanalítica da UFRJ.

2 Endereço para correspondência: Avenida Rui Barbosa, 460/1201, Flamengo. Rio de Janeiro. RJ. CEP 22250-020. Fone: (21) 2551-1903/ (21) 9588-8929. E-mail: eduardorotstein@gmail.com o conceito de inconsciente interroga, ao questionar, no campo que lhe é próprio, os lugares do sujeito e do objeto na elaboração do saber psicanalítico. O tratamento, por sua vez, só é possível sob transferência, laço que constitui uma objeção às exigências de objetividade, uma vez que ordena a prática clínica de acordo com a inclusão do analista nas séries psíquicas do analisante, conferindo ao primeiro um lugar na economia subjetiva do segundo e eliminando a exterioridade de um suposto observador, característica das condições controladas de um experimento científico.

$\mathrm{O}$ cientificismo de Freud encontra-se expresso no anseio de angariar o reconhecimento epistêmico à psicanálise, de evidenciar sua natureza de conhecimento de uma realidade, em oposição às construções dos sistemas filosóficos especulativos e às crenças obscurantistas e supersticiosas, cuja natureza ilusória e avessa ao conhecimento propriamente dito o conceito de inconsciente contribui para esclarecer.

De acordo com Jean-Claude Milner, a atitude cientificista de Freud corresponde ao assentimento dado ao ideal de ciência (Milner, 1996), o que envolve a distinção entre o ideal de ciência e a ciência ideal, na qual o primeiro se encarna. Enquanto o ideal de ciência instaura a aspiração de que a psicanálise seja uma ciência, a ciência ideal o traduz de modo datado e imaginário, invocando representações do fazer científico, múltiplas e aproximativas. Em seu caráter variável e não unívoco, tais representações permitem a Freud tanto sustentar o fundamento empírico da psicanálise quanto defini-la parcialmente como uma arte interpretativa, na contramão das ciências ideais que o inspiraram. 
A dimensão da experiência seria compartilhada por atividades de investigação e de tratamento psicanalíticos. Que concepção de experiência é suscetível de atender às condições de ambas? Investigaremos a etimologia do termo experiência, destacando as acepções presentes no texto freudiano; distinguiremos experiência e vivência; examinaremos a perspectiva de Freud sobre o método científico e o caráter empírico de sua investigação, para, ao final, abordarmos o caráter clínico da experiência psicanalítica.

Mesmo quando empregamos uma palavra movidos por clara intenção, ela pode vir a assumir também os outros sentidos que lhe são costumeiramente atribuídos no uso contemporâneo da língua. Do mesmo modo, é bem possível que os sentidos outrora assumidos por uma palavra ou por seus antecedentes estejam potencialmente contidos na mesma quando a empregamos no momento atual. Esta é a pressuposição da investigação etimológica, a qual, assim o atesta a etimologia do termo (derivado do adjetivo grego

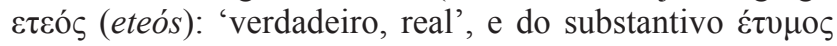
(étymos): 'verdadeiro sentido' (Bailly, 1901), procura o real sentido das palavras na suposta 'memória' que elas trazem consigo desde o seu remoto surgimento e que nelas perdura mesmo quando tenham adquirido, em virtude de reflexão ou simples transformação das práticas, um sentido diferente.

'Erfahrung' e 'experiência', respectivamente, no alemão e português correntes, designam hoje de modo predominante o ato de vivenciar, travar contato com algo pelos próprios sentidos, ou o saber obtido dessa maneira. Ambos têm raízes comuns na língua grega e latina e remontam a termos cujo sentido concreto se deixa entrever especialmente no termo alemão. Este se forma a partir do verbo 'erfahren', derivado de 'fahren'. Desde sua aparição até os dias atuais, 'fahren' conserva como sentido predominante 'viajar', 'percorrer uma extensão', via de regra, 'em direção a um lugar e por meio de algum veículo'. Sentido semelhante transmitiu-se, então, a 'erfahren', o qual passou gradualmente a designar também o ato de deslocar-se para colher alguma informação sobre alguém ou algo, para, finalmente, ter seu significado restringido a vivenciar, informar-se sobre algo por meio da percepção sensível, sem que esse ato tenha de ser precedido por qualquer atividade do experienciador (Grimm, 1984).

O substantivo grego $\pi$ cípa ('peíra') e o latino 'experientia' (traduzidos comumente por 'Erfahrung' ou 'experiência'), assim como os verbos a eles associados, respectivamente, $\pi \varepsilon 1 \rho \alpha ́ \omega$ ('peiráo'), e 'perior' (-iri) e 'experior' (-iri): 'tentar, fazer uma tentativa ou uma experiência sobre algo, pôr à prova, constatar pela própria experiência, empregar meios para alcançar algo' (Bailly, 1901; Gaffiot, 1934) remontam a um termo comum de sentido muito aproximado ao de 'fahren' e que constitui, mesmo, a provável origem deste

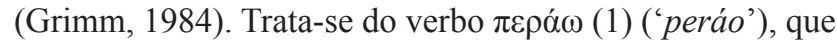
significa 'passar através; ir, avançar; atravessar algo'. Entre este termo originário e aqueles seus derivados, interpõe-se uma série reveladora de intermediários, relacionados àquele e entre si de modo semântico e morfológico (Curtius, 1866). Há os que expressam a ação de transportar para vender, ir vender, comerciar algo ( $\pi \varepsilon \rho \alpha ́ \omega ~(2)$ e 'pario' (-are)); alguns, via de comunicação ou caminho percorrido ( $\pi$ ópos ('póros')

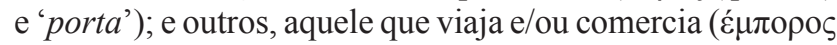
('émporos') e 'pararius'). Também há os que designam a ação de transportar algo proporcionando-o a alguém, ou de

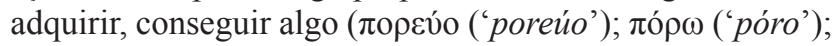
'pario' (-ere); enquanto outros, além da aquisição, designam ainda o ato de preparar-se para um empreendimento ou de aspirar a algo ('paro' (-are), cujo sentido já foi assumido por 'fahren' no passado) (Bailly, 1901; Gaffiot 1934).

As semelhanças morfológicas e semânticas que unem os termos acima a $\pi \varepsilon i ́ p \alpha$, 'experientia', 'Erfahrung' e 'experiência', sugerem o processo pelo qual estes se formaram: o avançar, atravessar uma extensão em direção a um lugar ( $\pi \varepsilon \rho \alpha ́ \omega(1))$ era o que também ocorria na maioria das trocas comerciais ( $\pi \varepsilon \rho \alpha ́ \omega(2)$ e 'pario' (-are)). Nessas viagens, traz-se algo consigo, sejam as mercadorias destinadas aos outros,

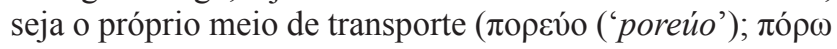
('póro'); 'pario' (-ere)); através delas também se alcançam as terras distantes e os produtos oriundos dessas terras (idem). Assim, o ato de deslocar-se logo se associa, por um lado, ao desejar algo, preparar-se para obtê-lo ('paro' (-are)) e realizar um empreendimento ( $\pi \varepsilon 1 \rho a ́ \omega$ ('peiráo'), e 'perior' (-iri) e 'experior' (-iri)); por outro, liga-se ao adquirir qualquer coisa, inclusive uma informação sobre algo (idem).

Descobrimos, então, que o sentido concreto desses termos sobrevive em 'experiência'. Assim como a condição para nos deslocarmos em direção a um lugar é não nos encontrarmos neste, assim como o anseio por algo e a tentativa de obtê-lo pressupõem não estarmos em sua posse, do mesmo modo, nossos sentidos dão-nos acesso a algo que não poderia ser alcançado através do exame da mera forma de nosso pensar, àquilo que, portanto, não se encontra desde sempre conosco. Ora, a existência e as propriedades do que se situa fora de nós podem ser atestadas apenas se nos 'transportamos' para junto deste. É o lançar-se em direção a algo que nos falta na tentativa de alcançá-lo, ‘o entrar em comércio', o que designa fundamentalmente 'experiência', mas também o conhecimento obtido em tal lançar-se, que, à maneira do saber dos viajantes sobre lugares distantes, não se deixa antecipar por revelação, adivinhação ou intuição intelectual, isto é, não pode advir de outro modo que pela viagem. ${ }^{3}$

A julgarmos pelas imagens que Freud evoca para ilustrar o saber não obtido por experiência, a seu ver oposto ao psicanalítico, vemos que sob sua pena conservou-se o sentido etimológico do termo. O filósofo, representante maior daquele tipo de saber ao lado do religioso, é o sujeito que "com seus barretes de dormir e com os trapos de seu roupão noturno (...) remenda as falhas do edifício do universo" (Freud, $1933 \mathrm{~b} / 1990$, p.173). A veste que completa o universo, sendo a trajada habitualmente durante o sono, alude sem dúvida ao trabalho onírico, que dá aos pensamentos a forma de objetos sensíveis; mas, sobretudo, por ser também esta a roupa usada no recesso do lar, simboliza o filósofo imóvel e recluso em seu próprio mundo, o mundo do puro pensamento, apartado da realidade exterior, e ainda assim acreditando conhecê-la através do mero jogo de suas representações. E mesmo que

3 Aliás, o termo latino 'periculum', igualmente derivado de $\pi \varepsilon \rho \alpha ́ \omega$ (1) (Curtius, 1866, p.245), pode significar tanto 'tentativa; experiência', quanto 'perigo' (Gaffiot, 1934). Isso dá esteio à seguinte analogia: assim como nas viagens podem ser perdidos os bens trazidos conosco, as experiências põem em risco a veracidade de nossas concepções antecipadas a respeito do investigado. No português, temos igualmente 'perigo', e no alemão, derivado patentemente de 'fahren', 'Gefahr'. 
porventura deixe o claustro das ideias para espiar o que se passa 'lá fora', ele despreza solenemente os dados que ameaçam a veracidade e a coerência do suposto saber a priori a que tanto se apega. Assemelha-se ao turista que só realiza suas excursões munido de um livrinho, um guia que lhe antecipa as atrações e o preserva de surpresas desagradáveis (Freud, 1926/1996, p.99). Em suma: o filósofo não viaja, ou apenas dissimula quando alardeia fazê-lo.

Em contrapartida, o psicanalista nutre o interesse de alcançar algo 'exterior', o psiquismo. Afirma amiúde que conhecê-lo desse modo significa, antes de tudo, não projetar nele concepções antecipadas sobre o ser humano, muitas vezes construídas a partir de expectativas e idealizações. Freud insiste que, para constituição do saber analítico, teve de fazer um exame de si próprio sem ceder um palmo aos preconceitos e às censuras intervenientes, que precisou acorrer aos outros com a mesma postura, mantendo-se firme na exploração do complexo de desejos sexuais que lhe era aberto; enfim, teve de correr riscos. Porém, a afirmação de que a psicanálise repousa em experiência diz mais do que isso.

\section{Da vivência de satisfação à experiência dos objetos}

Antes mesmo de instituir a experiência como o fundamento do saber analítico em seus pronunciamentos de cunho epistemológico, Freud já havia tematizado indiretamente a noção, desse modo reencontrando seu sentido originário. A investigação acerca das relações do psiquismo com a alteridade ensina que a assunção de algo exterior e independente de nós, assim como o interesse por conhecê-lo, estabelecem-se somente a partir de determinado momento, e que esse processo tem por condição uma falta em nós.

A tese freudiana sobre a natureza da experiência é cedo formulada (Freud, 1895/1996, 1900/1996), logo apresentada em termos estritamente psicológicos (Freud, 1900/1996, $1911 / 1982$ ) e retomada em momento tardio de sua obra (Freud,1925/1982), sem alterações significativas.

Nesses textos apresenta-se certa imagem do homem. Ao se o descrever sob a forma de um aparelho constituído de unidades discretas e de uma quantidade energética que as atravessa, pressupõe-se que está submetido a leis. A mais fundamental diz que cada uma dessas unidades constituintes tende a manter o estado desocupado de energia, de modo a se livrar imediatamente da quantidade recebida. Numa formulação mais geral, porém, ela diz que o aparelho tende a descarregar de imediato a energia recebida, sentida como desprazer, e que isso é feito por via motora. Essa lei, também chamada de 'princípio de inércia' ou 'princípio de prazer' (nesse ponto ainda indiferenciados), estabelece, portanto, conexão necessária entre energia e movimento, esclarecendo por que a idéia de uma quantidade energética distingue, segundo Freud, "a atividade do repouso" (1895/1996, p.347).

Duas são as fontes de movimento; valor diverso elas têm para a vida psíquica. Quando as estimulações provêm de fora, o aparelho logra descarregar a quantidade recebida, afastando-se imediatamente da fonte de estimulação, movimento reflexo designado de 'fuga do estímulo'. Mas também podem irromper estimulações no aparelho desde o interior do corpo. Estas não podem ser neutralizadas pela fuga, porque a fonte da qual emanam acompanha o psiquismo de modo constante. A via motora trará descarga efetiva da estimulação endógena somente se for realizada certa alteração no mundo exterior, a saber, se ao aparelho for apresentado um objeto adequado à sua cessação temporária. A presença de uma fonte constante de estimulação endógena corresponde a uma condição humana universal. $\mathrm{O}$ homem sempre está às voltas com necessidades relacionadas ao seu corpo, as quais só podem ser satisfeitas mediante a obtenção de algo que ele, de início, não possui. Sem recursos suficientes à obtenção do que carece, é-lhe indispensável ajuda alheia. Encontra-se, pois, em situação originária de falta e desamparo.

Se o devido auxílio é prestado ao desamparado e este efetua o reflexo, sobrevém-lhe a vivência de satisfação ( $B e$ friedigungserlebnis), isto é, a intensa descarga da estimulação endógena subseqüente às percepções daquele movimento e do objeto fornecido. A partir de então, cada novo acúmulo de energia endógena ficará associado aos elementos da vivência de satisfação, e à reprodução deste prazeroso evento estará condicionada sua descarga. Este acúmulo constitui doravante um estado de desejo (Wunschzustand); desejo, por sua vez, é a busca por reproduzir aquela vivência, e realização do desejo, a consumação disso, em especial a reprodução da percepção do objeto satisfatório.

De início, tenta-se realizar o desejo, segundo a tendência dominante à descarga imediata. Evoca-se com tamanha intensidade a representação do objeto satisfatório que esta ganha realidade; o representado é percebido como se estivesse novamente presente, ou seja, é alucinado. Trata-se de uma tentativa autocrática de realização do desejo, que consiste em dar-se a si próprio o objeto faltoso sem consideração ao que se passa fora. A alucinação indica haver, da parte do desejante, total indistinção entre o interno e externo, subjetivo e objetivo. Basta desejar algo para que este seja dado como existente.

O modo alucinatório de realização do desejo não perdura, contudo. A ausência da satisfação esperada, o desapontamento com a reprodução alucinatória daquela vivência leva à alteração deste procedimento em favor de um meio mais seguro de satisfação. Durante o estado de desejo, a evocação da situação passada é inibida em sua intensidade; já não conduz à alucinação do objeto, mas à sua reprodução enquanto mera representação, notadamente enquanto lembrança. De agora em diante, o aparelho suporta, sem descarregá-lo por via motora, o acréscimo de energia em seu interior até que lhe seja apresentada desde o exterior a percepção do objeto lembrado. Essa exigência recebe o nome de 'princípio de realidade', porque a percepção externa requerida à descarga serve como um índice de realidade (Realitätsanzeichen) do objeto procurado, isto é, de sua presença efetiva fora do aparelho, presença que, somente ela, permitiria aplacar o estado de desejo.

Ocorre que a admissão da realidade exterior não garante a realização do desejo, pois a percepção externa nunca oferece exatamente o objeto conservado na memória, do qual o objeto apresentado pelos sentidos diverge total ou parcialmente. Ao nos abrirmos ao exterior sempre somos surpreendidos por algo inesperado, e logo descobrimos que a promessa de restituição do objeto perdido não foi cumprida. A realidade sempre deixa a desejar; por isso sua admissão se 
faz necessariamente acompanhar de frustração e é substituída por modos de satisfação vizinhos à alucinação, como o sonho. Contudo, independentemente de sua eficácia para a realização do desejo, a admissão da realidade promove uma complexa atividade de pensamento, voltada ao acesso mais acurado à realidade e à sua transformação. Nessa atividade reconhece-se a origem do conhecimento do mundo mediante os sentidos.

Diante da dessemelhança entre o desejado e dado, o psiquismo atentará às nuances do material perceptivo, decompondo-o em seus elementos invariáveis e variáveis. Os primeiros são tratados como algo permanente em torno do qual se dispõem os segundos, como na relação entre uma coisa e seus acidentes (Freud, 1895/1996). Esta decomposição permite determinar com maior precisão o grau de diferença entre material perceptivo e a lembrança (se discordam totalmente ou se concordam apenas no tocante à substância, mas não em seus acidentes, por exemplo), e efetuar movimentos que modifiquem a situação perceptiva de modo a ajustá-la ao lembrado (Freud, 1895/1996). Assim, surgem movimentos que alteram a realidade segundo fins previamente estabelecidos; o reflexo torna-se agir (Handeln) (Freud, 1911/1982, p.20). Também já não é preciso estar sob o estado de desejo para colher percepções exógenas. As representações dos objetos assim percebidos são conservadas a despeito de não proporcionarem prazer imediato, e agora servem de critério a partir do qual se decide pela realidade de outras representações (Freud, 1911/1982, p.19).

Ao invés de reportadas a um estado subjetivo de intenso prazer, as representações o são agora a algo exterior; a vivência de satisfação dá lugar à experiência de objetos. Lembremos que, em sua epistemologia, Freud relaciona as diversas propostas de conhecimento à predominância do princípio de prazer ou ao de realidade. A ciência, cuja investigação baseia-se na experiência, opõe-se à religião e à filosofia, procurando apreender as conexões objetivas no material observado, mesmo que isso não renda prazer imediato e que tais conexões de início não se mostrem afins aos anseios humanos; aquelas investigações especulativas, ao contrário, tomam por objetivas, sem recurso à experiência, conexões simplesmente pensadas, as quais atendem ao inextinguível anseio por consolo diante da desventura da vida; a aparência metodológica da revelação, adivinhação, intuição intelectual ou dedução lógica, não deve enganar quanto a sua verdadeira natureza, a de "realizações de moções de desejo" (Freud, 1933b/1990, p.172). Por isso, os 'conhecimentos' assim obtidos são aproximados ora à psicose ora à neurose, quadros onde a função do real encontra-se de alguma forma abalada. Ao contrário, se, a exemplo do espírito científico, prioriza-se o acesso à realidade por experiência, descobre-se que nem sempre seus eventos tomam o curso que desejamos, que o mundo não é feito à imagem de nossas fantasias. "A experiência ensina-nos: $\mathrm{O}$ mundo não é nenhum quartinho de criança" (Freud, 1933b/1990, p.181).

Mas o reconhecimento da primazia da experiência no acesso ao exterior também não deve nos enganar quanto à verdadeira origem e função desta. A tese freudiana diz essencialmente que o interesse por conhecer não é primordial; deriva, na verdade, da busca por realizar um desejo: se admitimos a existência do mundo, se a ele nos voltamos a fim de experienciá-lo, é porque esperamos encontrar entre seus objetos aquele que nos falta e cuja obtenção traria satisfação. Mesmo quando uma atividade psíquica, de conhecimento ou não, exerce-se sem aparente satisfação, isso não implica que se desligou desse fim, senão que, através dela, sua obtenção consuma-se veladamente ou é adiada para um futuro distante, em que será mais segura. É o caso evidente da religião, mas também o da própria ciência, que se esforça ao máximo por resguardar da ânsia de satisfação sua investigação da realidade:

\begin{abstract}
"Um prazer momentâneo, incerto quanto a seus resultados, é abandonado, mas apenas para ganhar mais tarde, ao longo do novo caminho, um prazer seguro. Mas a impressão endopsíquica causada por esta substituição foi tão poderosa que se reflete num mito religioso especial. [...] as religiões puderam impor a renúncia absoluta de prazer na vida pela promessa de compensação numa existência futura; mas não alcançaram, por esta via, uma conquista do princípio do prazer. É a ciência que chega mais perto de obter êxito nessa conquista; ela, contudo, também oferece prazer intelectual durante seu trabalho e promete um lucro prático no final." (Freud, 1911/1982, p.22)
\end{abstract}

A admissão da realidade e a tentativa de investigá-la atendem à exigência de satisfação; não são contrários ao princípio do prazer. $\mathrm{O}$ fato de a psicanálise fundar-se sobre experiência de modo algum a subtrai à influência do desejo, que impulsiona todas as atividades humanas. A experiência em análise, assim como toda a experiência humana, é movida pela busca do que não se tem. Podemos indagar se a psicanálise chega algumas vezes a antecipar-se à sóbria investigação do psiquismo, atribuindo-lhe características ainda não encontradas na experiência. Mais: indagamos se é problemática a própria tarefa da investigação psicanalítica, uma vez que elege como principal objeto a ser alcançado 'lá fora' o psiquismo, a 'realidade psíquica', concebida como essencialmente inconsciente. A temática do inconsciente envolve a consideração a processos psíquicos imperceptíveis àquele mesmo que os comporta, e exige a todo momento que se ultrapasse o âmbito do sensível. Acaso a tese de que uma atividade desejante impulsiona secretamente qualquer atividade humana, inclusive o conhecimento do mundo por experiência, e deriva de alguma experiência? ${ }^{4}$ É notável que, ao final do artigo cujas passagens citamos, Freud (1911/1982), sutil, admita a vigência do princípio do prazer naquilo que acabara de deitar sobre o papel:

\begin{abstract}
"Nestas poucas frases sobre as conseqüencias psíquicas da adaptação ao princípio de realidade, fui obrigado a esboçar opiniões que teria preferido ainda reter e cuja justificação certamente custará esforço nada pequeno. Contudo, quero ter a esperança de que não escapará a leitores benevolentes onde, também neste trabalho, a dominância do princípio de realidade está começando." (p.24)
\end{abstract}

4 O prosseguimento nessa direção leva, sem dúvida, à metapsicologia, e à questão levantada pelo próprio Freud em torno de seu caráter especulativo, mas abordá-las seria exceder os limites do presente trabalho. 
É mister, agora, tratar em pormenor a noção de experiência tal como explicitada nas páginas psicanalíticas. É no discurso freudiano acerca do conhecimento que ela surge, não raro assumindo papel central na tarefa de legitimação da empresa psicanalítica. Esse discurso retira a ênfase da participação do desejo na experiência e acrescenta-lhe determinações não contidas no sentido originário da palavra. Só podemos compreendê-las, claro, se atentarmos a esse discurso, mas também ao contexto intelectual em que ele brota.

\section{Experiência como método de conhecimento científico}

Sabemos que o pensamento freudiano não é indiferente à discussão epistemológica travada no contexto intelectual onde ele surge; que se apropria, ademais, de certas teses e conceitos em voga, empregando-os na constituição de uma rudimentar teoria de conhecimento à luz da qual são descritas e avaliadas ciência, psicanálise e outras construções de pensamento. Essa autêntica 'epistemologia freudiana' (Assoun, 1983), aceita a tese então hegemônica de que o único conhecimento legítimo é o científico, e de que este não pode ser obtido senão através da experiência. Assim, a contundente afirmação de que a psicanálise é uma investigação empírica - feita, sobretudo, quando Freud se endereça ao público não-psicanalista a fim de introduzi-lo à nova e controversa disciplina - é também uma maneira de granjear-lhe o valioso título de ciência. Qual é, pois, o sentido reservado à 'experiência' nessas ocasiões, isso se deixa entrever com maior clareza apenas quando examinada a concepção dominante de ciência no mencionado contexto.

Na segunda metade do século XIX, o meio intelectual é dominado pela concepção de que o conhecimento científico é constituído exclusivamente por afirmações que podem corresponder a fatos, isto é, conexões entre dados sensíveis, e que a verdade das afirmações aufere-se pela sua efetiva correspondência aos fatos (Heidegger, 1987, p.67). Estão excluídas da ciência as afirmações inverificáveis através de observação, tais como as que visam a Deus, à alma e ao mundo (a totalidade dos fatos), assim como as apreciações estéticas e preceitos morais, que sequer pretendem reportar-se a estados-de-coisas. Se, por um lado, essa concepção serviu de base à feroz censura dirigida contra as pretensões cognitivas do método especulativo, que procede à formação e ampliação de conceitos sem recurso aos sentidos, por outro, deu impulso a uma série de desenvolvimentos acerca do método científico. Ora, muitos deles foram marcados pela filosofia de Kant.

Esta reflete sobre as condições subjetivas do fenômeno, relativas à nossa sensibilidade (pela qual as coisas nos são imediatamente dadas) e ao nosso entendimento (que permite ligar, mediante certas regras, o que é dado à sensibilidade), e tem por tarefa precípua provar que este último é estruturado por regras que presidem a ligação de todo e qualquer dado sensível, regras que constituem legítimas ferramentas para o conhecimento de algo de diferente do sujeito, digamos, as 'próprias coisas', não mais concebidas como existentes em si, mas como objetos dos sentidos. Ora, Kant vê na experiência $\mathrm{o}$ ato condicionado por regras universais mediante o qual acedemos aos objetos. Senão, vejamos:
A experiência (Erfahrung) é, de modo geral, 'um produto dos sentidos e do entendimento' (Kant, 1973, p.133), ou seja, não se compõe exclusivamente da recepção imediata de um múltiplo sensível, da qual se tem consciência, ou seja, da percepção (Wahrnehmung) pelos sentidos, mas também da atividade que conecta entre si um tal múltiplo. Portanto, a experiência não se esgota na passividade da percepção sensível (muito embora esta lhe seja imprescindível); pertence-lhe ainda um julgar sobre o percebido ${ }^{5}$. A rigor, porém, não lhe equivale qualquer julgar empírico. Certos juízos conectam entre si as percepções sensíveis de um modo tal que não concordam senão com o estado atual de um sujeito pensante, portanto, não valem necessariamente para este num momento diverso, nem para outros sujeitos. Tais juízos de validade restrita são chamados juizos de percepção (Wahrnehmungsurteile). Já outros, estabelecem uma conexão entre percepções sensíveis a partir de regras universalmente válidas, de modo a se exigir seu acordo com todos os juízos feitos sob as mesmas condições. Ora, quando os juízos devem sempre valer à pessoa que os profere e a quaisquer outras, então é porque não apenas correspondem à determinação de seu estado subjetivo, mas também de algo existente fora dela, isto é, concordam com uma disposição do objeto. Apenas a tais conexões, válidas objetivamente, reserva-se a designação juizos de experiência (Erfahrungsurteile).

O sentido e a função que a filosofia kantiana empresta à experiência foram em grande parte incorporados às reflexões de eminentes pesquisadores da época, cujos trabalhos teóricos exerceram influência decisiva sobre a epistemologia freudiana. Dentre eles destacam-se Claude Bernard, na França, e Ernst Mach, na Áustria. Ambos descreveram os próprios procedimentos e os de seus colegas, buscando deles extrair traços gerais da atividade científica; ambos também se ocuparam da aplicação do método científico ao estudo do homem. O primeiro sistematizou os princípios metodológicos da medicina científica, enquanto o segundo, além de ter dedicado seus próprios esforços à física e à psicofísica, foi uma espécie de difusor dos princípios adotados pelo grupo de cientistas (Fechner, Brücke, Helmholz, Du Bois-Reymond) a quem o jovem Freud e toda uma geração de psiquiatras se filiam (Assoun, 1983). Mach e Bernard nutrem a concepção geral de que a investigação científica repousa sobre experiência, entendendo por isso não a mera constatação de fenômenos, mas a atividade intelectual que busca o conhecimento das coisas através de uma determinada ordenação dos fenômenos e dos fatos.

A experiência é o termo de uma elaboração intelectual chamada 'raciocínio experimental'. Quem pauta suas investigações por este, sempre parte da constatação de um certo fenômeno, decompõe-no e pergunta quais elementos atuam em sua produção; em seguida, elege um ou alguns deles como suas possíveis causas. Uma tal conexão, que ainda não foi testada por observação, erige-a o investigador enquanto hipótese, ou seja, como afirmação cujo valor de verdade não está decidido, mas pode vir a sê-lo. Procura, então, fazer nova

5 ' $\mathrm{Na}$ base [da experiência] está a intuição, da qual estou consciente, isto é percepção (perceptio), que só concerne aos sentidos. Mas, em segundo lugar, também pertence a isso o julgar (que só convém ao entendimento)' (Kant, 1973, p.133). 
observação adequada para, enfim, confirmar ou infirmar a conexão hipotética. Somente esta última observação, previamente dirigida por uma questão e uma hipótese, constitui uma experiência.

Esta será tanto mais digna desse nome quanto maior a precisão das observações sobre as quais se exerce o raciocínio experimental. $\mathrm{O}$ investigador pode municiar-se de aparelhos que ampliam o alcance e a exatidão das observações; também pode, por meio desse recurso, manipular intencionalmente as condições de aparecimento do fenômeno estudado, produzindo situações até então inéditas, nunca encontradas in natura. Esse procedimento de justa execução do raciocínio experimental - a experimentação - mitiga a interferência enganadora das idiossincrasias do investigador sobre a experiência e reduz suas chances de extraviá-lo do caminho rumo aos próprios objetos; a experimentação confere à experiência maior objetividade e assegura à investigação genuíno valor científico (Bernard, 1915).

Em resumo: a experiência é o método de investigação da ciência; consiste na observação previamente orientada, segundo regras universais e procedimentos compartilháveis (de preferência experimentais), e rende um conhecimento ao mesmo tempo contingente e objetivo acerca das coisas existentes fora de nós. Quando Freud (1933b/1990) esclarece o modo de conhecimento científico como 'elaboração intelectual de observações cuidadosamente testadas' (p.171), resume com elegância a noção de experiência que herda do meio intelectual circundante. Mas ele não somente aceita a concepção então hegemônica de ciência, como também faz de suas características os critérios a serem preenchidos por toda investigação legítima. Com efeito, a maior parte das vezes em que esboça uma epistemologia, Freud também tece considerações gerais acerca da psicanálise, empenhando-se por aproximá-la ao máximo da ciência ideal. Nessas ocasiões a psicanálise é figurada de modo inequívoco como investigação empírica dos processos psíquicos inconscientes.

\section{A psicanálise como investigação empírica}

Não por acaso, os mais contundentes esclarecimentos acerca da psicanálise são dados quando Freud se endereça ao público leigo, especialmente em seus Dois Verbetes de Enciclopédia (1923/1990) e em algumas de suas novas conferências introdutórias, como Explicações, Aplicações e Orientações (1933a/1990) e Sobre uma Weltanschauung (1933b/1990). Nessas ocasiões, ele se encontra num momento avançado de sua trajetória intelectual, em que possivelmente se impunha a tarefa de assegurar à sua invenção um certo lugar junto às já reconhecidas construções de pensamento. Então, era mister fazer dela uma concepção inequívoca, que não legasse à posteridade dúvidas a respeito de sua natureza.

Se, por um lado, esses textos naturalmente oferecem material à investigação acerca dos fundamentos psicanalíticos, uma vez que o seu tema é a própria psicanálise e a tarefa de apresentá-la a tal público exige clareza e concisão dificilmente alcançadas em outras ocasiões, por outro, contudo, não bastam àquele intento, pois o vivo interesse em promovê-la leva amiúde à simplificação, omissão e até mesmo distorção de alguns de seus aspectos fundamentais. Logo no início do verbete 'Psicanálise' evidencia-se o primeiro de seus principais traços:

"Psicanálise é o nome de (1) um procedimento para a investigação de processos anímicos que de outro modo mal são acessíveis, (2) um método de tratamento (fundado nessa investigação) de distúrbios neuróticos e (3) uma série de conhecimentos psicológicos, obtidos por tal via, que gradualmente se erigem numa nova disciplina cientifica." (Freud, 1923/1990, p.253)

Distinguem-se claramente duas atividades no interior da psicanálise, embora fique em aberto a possibilidade de se exercerem através de meios comuns: a investigação (Untersuchung), isto é, a busca de conhecimento acerca dos processos psíquicos mencionados (inconscientes, diríamos) e o tratamento (Behandlung), a intervenção terapêutica sobre os distúrbios neuróticos. Conjugadas, elas proporcionam a aquisição de variados conhecimentos, cujo crescente acúmulo e organização leva à formação de uma disciplina diferente das demais existentes, contendo conceitos e princípios próprios.

A nítida discriminação entre investigação e tratamento parece análoga à distinção clássica entre teoria e prática ${ }^{6}$; na psicanálise, as duas atividades entretêm uma relação hierárquica bem definida. Listado em primeiro lugar, o procedimento investigativo condiciona o exercício terapêutico: para que se intervenha sobre o psiquismo é preciso conhecê-lo, não o inverso. A dependência da atividade prática à teórica não significa, contudo, que esta seja um meio à realização daquela, ou seja, que se investigue o psiquismo apenas na medida em que se intente tratá-lo. Com efeito, a investigação visa a alcançar verdades universalmente válidas, ao passo que a terapêutica, voltada a um sujeito que sofre, nunca se desliga de interesses particulares; o conhecimento apresenta-se, assim, como um fim mais nobre, para o qual devem convergir os esforços da psicanálise. Com o intuito de dissipar certos equívocos gerados pela difusão de suas ideias no meio social, Freud (1933a/1990) salienta a prevalência da atividade e interesse teóricos na psicanálise:

"Disse-lhes que a psicanálise começou como uma terapia; mas não quis recomendá-la ao interesse dos senhores como terapia, mas sim por causa do seu conteúdo de verdade, por causa dos esclarecimentos que nos dá a respeito daquilo que concerne o mais de perto os seres humanos - sua própria essência-e por causa das conexões que ela desvenda entre as mais diversas de suas atividades." (p.169)

O segundo e mais importante traço da imagem freudiana de psicanálise evidencia-se, sobretudo, em Sobre uma Wel-

6 Sabemos que ela provém do antigo mundo grego. 'Theoria' é um substantivo derivado do verbo 'horân', que significa ver ou observar, enquanto 'práxis' é uma substantivação do verbo 'práttein', agir. (Bailly, 1901; Delotte, 1953). Como nos ensinam Jaeger (2003, p.190-229) e Koyré (1991, p.243-251), 'theoría' designa uma investigação cujo fim exclusivo é a apreensão das características essenciais do que é investigado (podemos discernir ainda outra significação, bastante usual, segundo a qual 'teoria' se refere antes ao resultado de uma tal investigação, isto é, ao saber assim obtido). Já 'práxis' nomeia o curso de ações humanas cujo fim não é a contemplação da realidade, mas a transformação dela segundo interesses particulares. Pudéssemos resumir os tipos de questão de que se ocupam qualquer theoría e práxis, diríamos que a primeira pergunta 'o que é...?', ao passo que a segunda, 'o que fazer para...?'. 
tanschauung. Sob a tarefa de responder a uma questão que ele próprio levantara, a saber, se a psicanálise conduz a uma visão de mundo, Freud apresenta o cerne de sua concepção epistemológica, examinando, a partir dela, a psicanálise e outras construções de pensamento.

A resposta é contundente: se entendermos por Weltanschauung uma construção intelectual que, baseada numa suposição fundamental, confere inteligibilidade a todas as coisas e oferece orientação segura à conduta humana, então a psicanálise não pode conduzir a uma. Tal construção, empreendida muitas vezes pela filosofia e sempre pela religião, impõe-se ao espírito humano devido à sua aptidão em satisfazer a exigência de consolo e proteção diante dos dolorosos infortúnios da vida. Sem negar a presença e o poder desses anseios sobre a vida psíquica, para cuja descoberta, aliás, ela própria contribuiu, a psicanálise sobrepõe-lhes um outro, não tão espontâneo: quer, antes de tudo, conhecer a realidade, dirigindo-o especialmente ao psiquismo inconsciente. No entanto, o interesse teórico não basta, por si só, ao embargo de uma Weltanschauung; pois religião e filosofia, que reclamam validade objetiva às suas construções, tomadas por límpido espelho do mundo, crêem-se também animadas pelo mesmo interesse.

A questão é decidida pelo modo como a psicanálise exerce o interesse teórico. Ela conduz sua investigação segundo o método de conhecimento da ciência, o qual julga a única via legítima de acesso à realidade. "Não há', diz Freud a propósito do pensamento científico, 'nenhuma outra fonte do conhecimento do mundo que a elaboração intelectual de observações cuidadosamente testadas (...); ao seu lado nenhum conhecimento advindo de revelação, intuição ou adivinhação" (Freud, 1933b/1990, p.171). E assim descreve, em seu interesse e método, o pensamento a que a psicanálise adere:

"O pensamento científico não é diferente, em sua essência, da atividade normal de pensamento que nós todos (...) empregamos na ocupação de nossos assuntos na vida. Ele apenas desenvolveu-se especialmente em alguns aspectos, interessa-se por coisas que não têm uso imediato, tangivel; esforça-se por manter cuidadosamente à distância fatores individuais e influências afetivas; prova mais rigorosamente a credibilidade das percepções sensiveis [Sinneswahrnehmungen] nas quais baseia suas conclusões; provê-se com novas percepções, que não se podem obter pelos meios habituais, e isola as condições dessas novas experiências [Neueerfahrungen] em tentativas intencionalmente modificadas. Seu anseio é alcançar a concordância com a realidade, isto é, com o que existe fora de nós, independentemente de nós e, como nos ensinou a experiência, é de papel decisivo para a realização ou frustração de nossos desejos". (Freud, 1933b/1990, p.184).

Com o fim último de conhecer a realidade - 'cujo papel é decisivo para a realização ou frustração de nossos desejos' - o pensamento científico conduz-se por um raciocínio e certos procedimentos investigativos, aparentemente os mesmos identificados pela tradição epistemológica então hegemônica. Essa elaboração intelectual, porém, não teria qualquer valor se apartada do material sensível; a atividade de conhecimento inicia-se com a percepção sensível e dela nunca pode inteiramente se afastar, pois é o único índice possível da presença de algo exterior. A investigação conduzida sob o pensamento científico dirige-se a um mundo ou a uma realidade entendida de modo mais restrito que 'o conjunto das coisas em geral', limita-se ao conjunto das coisas enquanto nos aparecem, dos fenômenos, os quais, é certo, admitem algum controle, mas não são inteiramente antecipáveis em seu conteúdo. É impossível à investigação psicanalítica erigir uma Weltanschauung porque, sendo o seu método a experiência, nunca rende explicações definitivas e válidas à totalidade das coisas. Se ainda é lícito falar de uma cosmovisão erguida a partir de investigação empírica, seria fragmentária e inacabada, afastar-se-ia tanto de uma visão de mundo em sentido estrito, que haveríamos de questionar-lhe essa designação.

O caráter de contingência, que ao lado do de objetividade, indica a procedência empírica do conhecimento, não raro é atribuído por Freud às suas próprias formulações teóricas. Antes que uma fraqueza a ser ocultada, a contingência parece-lhe mesmo algo a ser sublinhado como atestado de cientificidade da psicanálise. No verbete de enciclopédia sobre a teoria da libido, lemos na seção intitulada 'Caráter da Psicanálise como Ciência Empírica’:

\footnotetext{
"A psicanálise não é, como as filosofias, um sistema que parta de alguns conceitos básicos nitidamente definidos, que procura apreender todo o universo com o auxílio deles, e, então, uma vez completo, não possui lugar para novas descobertas ou melhores compreensões. Antes, ela se atém aos fatos de seu campo de estudo, procura resolver os problemas mais próximos da observação, sonda o caminho à frente com o auxílio da experiência, está sempre incompleta e sempre pronta a corrigir ou a modificar suas teorias." (Freud, 1923/1990, p.269).
}

A figuração da psicanálise como investigação empírica é fruto de uma tendência, patente nos textos incumbidos de sua divulgação, de assimilá-la à ciência. Como conseqüência, falta-lhes maior reflexão acerca da eventual peculiaridade da experiência feita em análise em relação às demais experiências científicas. Afora a especificidade das regiões fenomênicas a que se aplicam, seriam essencialmente iguais. Contudo, mesmo dominado por essa tendência, Freud indica um aspecto distintivo da experiência analítica, a princípio não concernente ao objeto, mas ao seu modus operandi: "Só que, na análise, deve-se abrir mão da ajuda que o experimento [Experiment] presta à pesquisa" (Freud, 1933b/1990, p.188).

Esse apontamento, meramente negativo, leva-nos à indagação das características positivas da experiência analítica. Temos, então, de saltar dos textos comprometidos com a apologia da 'jovem ciência', onde ela é apresentada como uma investigação baseada na experiência enquanto sistemática da observação, e onde se menciona apenas brevemente a motivação última de toda a experiência: o desejo pelo objeto satisfatório. Vamos, agora, aos textos votados à descrição dos procedimentos postos em jogo numa análise.

\section{O caráter clínico da experiência analítica}

Se a experiência analítica equivalesse a uma sistemática da observação, então o consultório seria tal e qual um labora- 
tório. Mas isso não procede: na análise, deve-se prescindir do experimento. O que, por sua vez, é imprescindível à análise, dizem-nos os relatos de caso e os artigos sobre a técnica, escritos de Freud mais votados à formação do analista que à divulgação da psicanálise. A partir deles vemos formar-se uma concepção de experiência em franca divergência com a explicitada nas palestras.

E conhecida a analogia entre o processo de análise e o jogo de xadrez (Freud, 1913/1996, p.137). Apenas a abertura e o final das partidas de xadrez prestam-se a uma descrição sistemática e exaustiva como a oferecida pelos livros especializados; já o curso da partida entre esses dois momentos desdobra-se segundo infinitas possibilidades e não admite uma tal descrição. A analogia, feita para iluminar as limitações ao exercício da análise, ainda pode ser investida de maior alcance: assim como o jogo de xadrez, o processo de análise não é solitário, não pode ser iniciado e desenvolvido por vontade de um só. Nele têm assento dois participantes, o que conduz a análise e o que a ela se submete, o analista e o analisando. Este padece de uma falta, demanda ao outro seu preenchimento e desse modo acredita poder alcançá-lo. Portanto, antes de tudo, também o analisando busca realizar uma experiência.

O caráter 'produtor' dos dispositivos analíticos é crucial: ao acolher as associações, o analista ganha importância diante do analisando, o processo analítico insere-se no restante de sua vida e imiscui-se em seus desejos e fantasias. O movimento de 'voltar-se' à situação analítica, em especial à figura do analista, concedendo-lhe um lugar privilegiado na própria vida psíquica, chama-se 'transferência'. Ora, à medida que o laço transferencial se estreita, mais iminente torna-se a emergência de desejos e fantasias relacionados ao conflito neurótico; no entanto, o reconhecimento de impulsos inaceitáveis gera tamanho desprazer que amiúde resiste-se à rememoração de eventos passados. Nesse momento, inflexíveis em sua exigência de satisfação, eles encontram expressão por uma via alternativa à verbalização, uma ação motora que os reproduz. A transferência em análise não favorece apenas a emergência de desejos sob a forma de recordação, isto é, do relato de eventos passados relacionados a eles, mas de uma incontornável atuação. $\mathrm{O}$ analisando age como outrora sem vivenciá-lo como algo passado, mas como um vínculo atual com o analista. Ao invés de narrativa, o desejo emerge como drama.

O abandono da análise por Dora constitui um dos mais célebres exemplos de atuação (Freud, 1905/1996). Lembremos que após ter respondido com uma bofetada à proposta do Senhor K., por quem nutria inconfesso desejo sexual, a moça levou 14 dias sem relatar o ocorrido a ninguém. Tinha esperança de que nesse período o amado reiterasse sua proposta. Como houvesse terminado o prazo e ele não tivesse dado mostras da seriedade de suas intenções, a moça, num gesto de vingança, denunciou-o aos pais. Tempos depois, Dora anuncia a Freud sua saída da analise, tendo tomado a decisão 14 dias antes. Assim, portou-se diante do analista do mesmo modo que outrora diante do amado, com a diferença de o abandono ter sido, desta vez, a via encontrada para a atualização do desejo de vingança.

Enquanto induz à atuação do desejo, a transferência constitui um empecilho aos fins da análise; no entanto, através de atuação, primeiramente, costumam mostrar-se os motivos do sofrimento neurótico. Os desejos e conflitos pertencentes a uma neurose só podem ser conhecidos e sofrer intervenção quando se tornam manifestos e imediatos os impulsos relacionados a ela; caso contrário, se não se os atualiza, a neurose permanece inacessível à análise. Como diz Freud, "é impossível vencer um inimigo ausente ou fora de alcance" (1912/1996, p.119; 1914/1996, p.168). Assim, a transferência provoca a própria condição patológica que se pretende analisar, e somente desse modo é possível investigá-la. A expressão freudiana 'neuroses de transferência' indica, por sinal, este duplo reconhecimento: por um lado, o processo patológico, pelo fato mesmo de ter sido suscitado em análise, difere do que havia antes; por outro, tal processo constitui uma genuína neurose, sobre a qual devem voltar-se os objetivos da análise (Freud, 1914/1996).

Seria, pois, a atualização do conflito neurótico sob transferência como a produção controlada de um fenômeno, procedimento que permitiria isolar os componentes do distúrbio e avaliar com precisão o papel de cada um deles em sua deflagração? Que a inegável participação dos dispositivos de análise sobre as manifestações ocorridas em seu âmbito dê margem a aproximar experiência analítica de experiência científica, isso é compreensível, mas de modo algum justificável. Essa aproximação só pode ser feita às custas da negligência de uma condição fundamental da transferência e de todo o processo analítico, condição aludida na analogia com o xadrez.

Para o estabelecimento da transferência contribui ativamente o analisando, que percebe o analista conforme suas fantasias, reservando-lhe, não raro, o lugar do objeto amado e odiado; também é o autor do script de sua atuação compulsiva. A necessária participação do analisando no processo condiciona o estabelecimento da transferência, ao mesmo tempo em que impede o total manejo das manifestações produzidas sob ela. A experiência analítica não equivale à experiência científica porque nela o suposto objeto de investigação também realiza a experiência. Não um espaço experimental, onde vige a relação unilateral e impessoal do pesquisador com o objeto, o laço da análise é um lugar onde se interage e atua, assemelha-se a um playground (Freud, 1914/1996) que, às vezes, transmuta-se em campo de batalha, como o simula um tabuleiro de xadrez.

Há ainda um outro traço da análise que contribui para dar à sua experiência um caráter peculiar. Esta se distingue da experiência científica, porque satisfaz simultaneamente, através dos mesmos procedimentos, o interesse prático e teórico: ela conhece o psiquismo no mesmo golpe em que promove o seu tratamento.

O duplo aspecto teórico e prático da psicanálise não lhe renderia, por si só, a pecha de "uma disciplina de tipo incomum" (Freud, 1911/1990, p.724), uma vez que também na medicina moderna conjugam-se pesquisa e tratamento (Bernard, 1915). A diferença encontra-se no fato de que, nesta, a atividade de tratamento não coincide com a de investigação e encontra-se subordinada a esta, enquanto na psicanálise são inseparáveis. Os procedimentos que possibilitam o conhecimento das neuroses quase sempre são os que, ao mesmo tempo, propiciam uma transformação desses estados, e vice-versa: a associação-livre, por exemplo, ao favorecer o abrandamento da autocensura, permite a evocação de um 
material psíquico de outro modo silenciado, o qual se supõe ter íntima relação com a causa dos sintomas.

Depreendida dos escritos freudianos, a ausência de centro de referência, e a indissociabilidade dos aspectos teórico e prático são dois traços da experiência analítica que constituem o seu caráter clínico. Por si só, ele impede a equivalência da experiência analítica com uma sistemática da observação. No entanto, permanece implícito que na análise não seja em absoluto questão de observação. A concepção de experiência analítica, aquela sustentada por Freud quando se dirige ao leigo em psicanálise, permanece a de uma experiência que preenche a função predominante de meio de conhecimento.

\section{Conclusão}

A obra freudiana reserva ao menos dois sentidos a 'experiência': um deles liga-se à origem do termo e está implícito na tese segundo a qual um desejo motiva todas as atividades humanas: a experiência é um 'transportar-se para fora' na tentativa de alcançar algo que não se tem e cuja obtenção traria satisfação. O outro provém da tradição epistemológica a que Freud se filia, e está explicitado em seu discurso sobre a ciência: a experiência é o método científico de conhecimento, oposto à especulação, que consiste na observação previamente ordenada de fenômenos, conforme a princípios e procedimentos compartilháveis. É verdade, esse sentido não contradiz o originário, pois concebe uma atividade como condição da experiência, portanto, distinta da mera vivência. Ainda assim, afasta-se daquele na medida em que negligencia a natureza desejante dessa atividade e a restringe ao controle de observações. Apesar disso, este sentido é o adotado por Freud em seu esclarecimento da psicanálise como investigação empírica, quando se trata de defender o caráter científico de sua invenção. Sua divergência em relação à descrição da experiência analítica nos artigos técnicos e relatos de caso pelos quais se evidencia seu caráter clínico - mantêm uma tensão no seio de sua concepção de experiência.

Em ambos os sentidos, afirma-se o fundamento empírico da psicanálise e a abertura da teoria à invenção e à renovação. Parafraseando Goethe, que comparara o cinza da teoria ao verde da árvore dourada da vida, Freud (1924/1996) recomenda "um retorno proveitoso da cinzenta teoria para o verde perpétuo da experiência" (p. 189).

\section{Referências}

Assoun, P.-L. (1983). Introdução à Epistemologia Freudiana. Rio de Janeiro: Imago (Trabalho original publicado em 1981).

Bailly, A. (1901). Abrégé du Dictionnaire Grec-Français. Paris: Hachette.

Bernard, C. (1915). Introduction à l'Étude de la Médicine Experimentale. Paris: Delagrave (Originalmente publicado em 1865).

Curtius, G. (1866). Grundzüge der Griechischen Etymologie. Leipzig: B.G. Teubner. (Trabalho original publicado em 1858) Delotte, A. (1953). Le Verbe grec. Paris: Librairie C. Klincksieck.
Freud, S. (1982) Formulierungen über die zwei Prinzipien des psychischen Geschehens. In A. Mitscherlich. (Ed.) Die FreudStudienausgabe (vol. 3, pp. 17-24). Frankfurt am Main: Fischer. (Trabalho original publicado em 1911)

Freud, S. (1982) Die Verneinung. In A. Mitscherlich (Ed.) Die Freud-Studienausgabe (vol. 3, pp. 371-377). Frankfurt am Main: Fischer. (Trabalho original publicado em 1925)

Freud, S. (1990). Über Grundprinzipien und Absichten der Psychoanalyse. In A. Freud (Ed.) Gesammelte Werke (vol.19, pp. 724-729). Frankfurt am Main: Fischer. (Trabalho original publicado em 1911).

Freud, S. (1990). Psychoanalyse und Libidotheorie. In A. Freud (Ed.) Gesammelte Werke (vol. 13, pp. 211-231). Frankfurt am Main: Fischer. (Trabalho original publicado em 1923).

Freud, S. (1990). Erklärungen, Anwendungen und Orientierungen. In A. Freud (Ed.) Gesammelte Werke (vol. 15, pp. 153-169). Frankfurt am Main: Fischer. (Trabalho original publicado em 1933)

Freud, S. (1990). Über eine Weltanschauung. In A. Freud (Ed.) Gesammelte Werke (vol. 15, pp. 170-197). Frankfurt am Main: Fischer. (Trabalho original publicado em 1933).

Freud, S. (1996). Projeto de uma Psicologia Científica. In J. Strachey (Ed.) Edição Standard das Obras Psicológicas Completas de Sigmund Freud (vol. 1, pp. 347-449). Rio de Janeiro: Imago. (Trabalho original publicado em 1895).

Freud, S. (1996). A Interpretação do Sonho. In J. Strachey (Ed.) Edição Standard das Obras Psicológicas Completas de Sigmund Freud (vols. 4 e 5, pp. 39-735) Rio de Janeiro: Imago. (Trabalho original publicado em 1900).

Freud, S. (1996). Um caso de Histeria. In J. Strachey (Ed.) Edição Standard das Obras Psicológicas Completas de Sigmund Freud (vol. 7, pp. 19-119). Rio de Janeiro: Imago. (Trabalho original publicado em 1905).

Freud, S. (1996) A Dinâmica da Transferência. In J. Strachey (Ed.) Edição Standard das Obras Psicológicas Completas de Sigmund Freud (vol. 12, pp. 111-123). Rio de Janeiro: Imago. (Trabalho original publicado em 1912).

Freud, S. (1996) Sobre o Início do Tratamento. In J. Strachey (Ed.) Edição Standard das Obras Psicológicas Completas de Sigmund Freud (vol. 12, pp. 139-161). Rio de Janeiro: Imago. (Trabalho original publicado em 1913).

Freud, S. (1996) Recordar, Repetir e Elaborar. In J. Strachey (Ed.) Edição Standard das Obras Psicológicas Completas de Sigmund Freud (vol. 12, pp. 163-175). Rio de Janeiro: Imago. (Trabalho original publicado em 1914).

Freud, S. (1996) Neurose e psicose. In J. Strachey (Ed.) Edição Standard das Obras Psicológicas Completas de Sigmund Freud (vol. 19, pp. 167-175). Rio de Janeiro: Imago. (Trabalho original publicado em 1924).

Freud, S. (1996) Inibição, Sintoma e Angústia. In J. Strachey (Ed.) Edição Standard das Obras Psicológicas Completas de Sigmund Freud (vol. 20, pp. 153-175). Rio de Janeiro: Imago. (Trabalho original publicado em 1926).

Gaffiot, F. (1934). Dictionnaire Latin-Français. Paris: Hachette.

Grimm, J. et W. (1984). Deutsches Wörterbuch von Jacob Grimm und Wilhelm Grimm. 16 Bde. [in 32 Teilbänden]. München: Deutsches Taschenbuch (DTV) (Trabalho original publicado em 1862).

Heidegger, M. (1987). Que é uma coisa? Lisboa: Edições 70. 
Jaeger, W. (2003). O pensamento filosófico e a descoberta do cosmos. In Paidéia: A Formação do Homem Grego (pp.190229). São Paulo: Martins Fontes (Trabalho original publicado em 1936).

Kant, I. (1973). Prolegômenos. São Paulo: Abril. (Coleção Pensadores, Vol. XXV). (Trabalho original publicado em 1783).

Koyré, A. (1991). Os Filósofos e a Máquina. In: A. Koyré (Ed.) Estudos de História do Pensamento Filosófico. Rio de Janeiro: Forense Universitária. (pp.243-251). (Trabalho original publicado em 1948)
Milner, J-C (1996). A obra clara: Lacan, a ciência, a filosofia. Rio de Janeiro: Jorge Zahar.
Recebido em 02.03.2010 Aceito em 29.06.2010 